\title{
Perlindungan Hak Paten Pada Produk ASUS
}

\author{
Mas Agus Eliyani \\ 155100047 \\ Fakultas Komputer, 448757169 \\ masaguseliyani.student@umitra.ac.id
}

\begin{abstract}
ASUS, is a Taiwan-based company that manufactures computer components such as motherboards, graphics cards, and notebooks. Asus recently began producing PDAs, mobile phones, LCD monitors, tablets and other computer products. Its main competitors including MSI, and Gigabyte.Asus in 2005 sold more motherboards than other companies, including 30 million in 2004. This figure includes other brand contracts. Asus also manufactures components for other companies, including PS2 Sony and Apple Ipod, iBook, etc. ASUS has been chosen by many users because it dares to provide a 2-year warranty for notuytv products it made. in Indonesia and managed to become the number one brand to date (according to IDC and GFK data). Asus which is a "Public" company has registered on the floor of the Taiwan Stock Exchange with code 2357 and a secondary list on the London Stock Exchange with ASKD code.
\end{abstract}

Keywords: ASUS Patent Protection

\section{A. INTRODUCTION}

ASUS is the world's third largest notebook manufacturer and the best-selling awardwinning motherboard in the world. As a pioneer in the digital era, ASUS designs and manufactures a variety of products that meet flawless needs and offices, through various products such as motherboards, graphics cards, optical drives, monitors, desktop computers, and All-inone PCs, notebooks, servers, multimedia devices, wireless solutions, internet network devices, tablets, smartphones and wearable gadgets. driven by innovation and commitment to always create quality products.

ASUS has provided fast and reliable protection for cellphones or laptops and can adapt power-efficient processor technology and dedicated graphics card support for multimedia.

\section{B. CONCLUSION}

By using technology patented by ASUS, we can complete various activities that we have 
even though they are used up to 48 hours nonstop the engine performance will remain smooth.

\section{ACKNOWLEDGEMENT}

University Of Indonesia

University Of Mitra Indonesia

Telkom University

University Of Mellbourne

Saitama University

[1] A. S. Putra And O. M. Febriani, "Knowledge Management

Online Application In Pdam 
Lampung Province," In Prosiding International Conference On Information Technology And Business (Icitb), 2018, Pp. 181-187.

[2] A. S. Putra, O. M. Febriani, And B. Bachry, "Implementasi Genetic Fuzzy System Untuk Mengidentifikasi Hasil Curian Kendaraan Bermotor Di Polda Lampung," J. Sist. Inf. Dan Manaj. Basis Data, Vol. 1, No. 1, Pp. 21-30, 2018.

[3] O. M. Febriani And A. S. Putra, "Sistem Informasi Monitoring Inventori Barang Pada Balai Riset Standardisasi Industri Bandar Lampung," J. Inform., Vol. 13, No. 1, Pp. 90-98, 2014.

[4] Putra, Arie Setya. "2018 Artikel Struktur Data, Audit Dan Jaringan Komputer." (2018).

[5] Putra, A. S. (2018, July 17). Paperplain Fundamental Create Application With Borland Delphi 7.0 University Of Mitra Indonesia. Retrieved From Osf.Io/Pbrn9.

\section{E. REFERENCE(Based APA )}

Putra, A. S., Aryanti, D. R., \& Hartati, I. (2018, November). Metode SAW (Simple Additive Weighting) sebagai Sistem Pendukung Keputusan Guru Berprestasi (Studi Kasus: SMK Global
Surya). In Prosiding Seminar Nasional Darmajaya (Vol. 1, No. 1, pp. 85-97).

Sari, D. P., Febriani, O. M., \& Putra, A. S. (2018, November). Perancangan Sistem Informasi SDM Berprestasi pada SD Global Surya. In Prosiding Seminar Nasional Darmajaya (Vol. 1, No. 1, pp. 289-294).

Putra, A. S. (2018). Paperplain: Execution Fundamental Create Application With Borland Delphi 7.0 University Of Mitra Indonesia.

Putra, A. S., Sukri, H., \& Zuhri, K. Sistem Monitoring Realtime Jaringan Irigasi Desa (JIDES) Dengan Konsep Jaringan Sensor Nirkabel. IJEIS (Indonesian Journal of Electronics and Instrumentation Systems), 8(2), 221232.

Darmawan, A., Yuliawati, D., Marcella, O., \& Firmandala, R. (2016). Sistem Absensi dan Pelaporan Berbasis Fingerprint dan SMS Gateway. EXPLORE, 7(1).

Febriani, O. M., Wahyuni, T., \& Yusuf, S. (2017). DESIGN OF WEBSITE-BASED INFORMATION SYSTEM FOR EDOCUMENT ADMINISTRASI IN THE COMMUNITY SERVICE UNIT (A Case Study at Rajabasa District). INTERNATIONAL JOURNAL OF COMPUTERS \& TECHNOLOGY, 16(7), 7010-7020.

Febriani, O. M., \& Wahyuni, T. (2017, October). PERANCANGAN SISTEM E-DOCUMENT ADMINISTRASI LOGBOOK PENELITIAN PADA 
UNIT LAYANAN DI BANDAR LAMPUNG. In Prosiding Seminar Nasional Darmajaya (Vol. 1, No. 1, pp. 187-194).

Febriani, O. M., \& Permadi, A. B. (2017). Implementasi Sistem Aplikasi Data Bimbingan dan Pelanggaran Siswa pada Sekolah Menengah Atas di Lampung Tengah dengan Metode Analisis dan Desain Sistem Terdistribusi (SSAD). EXPERT, 7(1).

Febriani, O. M., \& Ambarwati, L. (2015). PERANCANGAN APLIKASI PENGOLAHAN DATA PENJUALAN UKM KELANTING KHAS TELO DESA SIDOHARJO KECAMATAN JATI AGUNG KABUPATEN LAMPUNG SELATAN. Jurnal Teknologi Informasi dan Bisnis Pengabdian Masyarakat Darmajaya, 1(1), 77-95.

Febriani, O. M. (2015). Rancang Bangun Aplikasi Ecommercemenggunakan Freewebstore pada UKM Kelanting di Desa Sidoharjo Lampung Selatan. Prosiding Sembistek 2014, 1(02), 446-458. 